Tjalling C. Koopmans Research Institute Tplligh Aoopman

Discussion Paper Series nr: 11-16

\title{
Gravity Models of Trade-based Money Laundering
}

Joras Ferwerda Mark Kattenberg Han-Hsin Chang Brigitte Unger Loek Groot Jacob A. Bikker 


\section{Tjalling C. Koopmans Research Institute Utrecht School of Economics \\ Utrecht University}

Janskerkhof 12

3512 BL Utrecht

The Netherlands

telephone $\quad+31302539800$

fax +31302537373

website www.koopmansinstitute.uu.nl

The Tjalling C. Koopmans Institute is the research institute and research school of Utrecht School of Economics.

It was founded in 2003, and named after Professor Tjalling C. Koopmans, Dutch-born Nobel Prize laureate in economics of 1975.

In the discussion papers series the Koopmans Institute publishes results of ongoing research for early dissemination of research results, and to enhance discussion with colleagues.

Please send any comments and suggestions on the Koopmans institute, or this series to J.M.vanDort@uu.nl

ontwerp voorblad: WRIK Utrecht

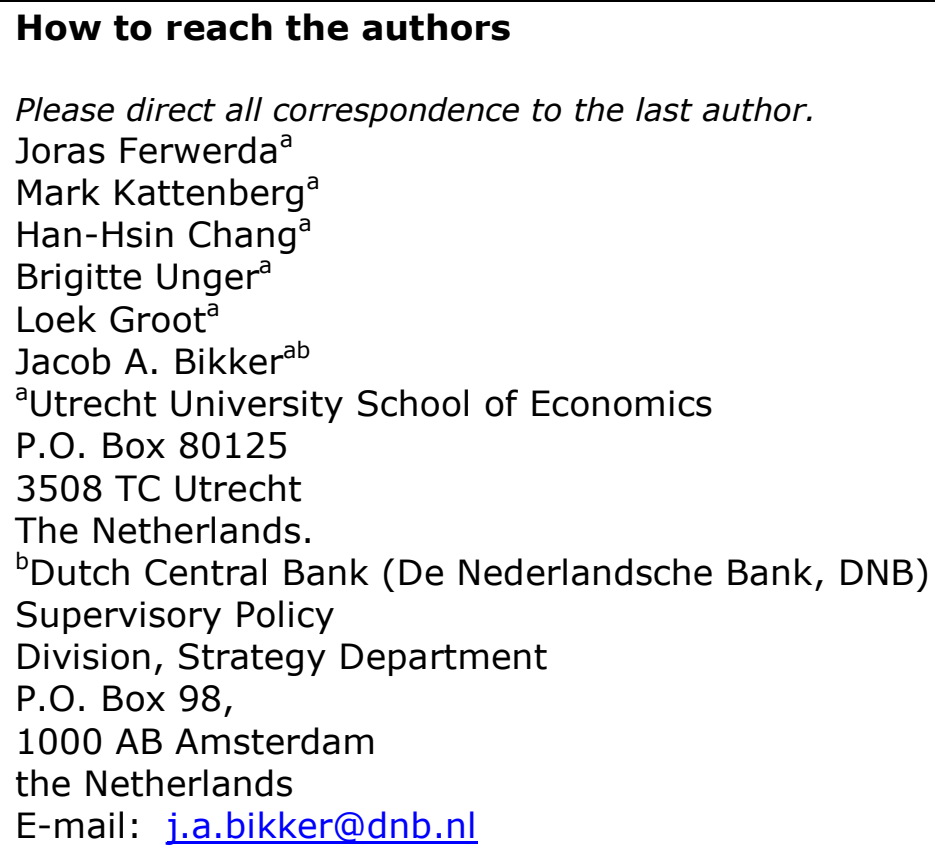


Utrecht School of Economics

Tjalling C. Koopmans Research Institute

Discussion Paper Series 11-16

\title{
Gravity Models of Trade-based Money Laundering
}

\author{
Joras Ferwerda \\ Mark Kattenberga \\ Han-Hsin Changa \\ Brigitte Unger \\ Loek Groot ${ }^{a}$ \\ Jacob A. Bikker ${ }^{\mathrm{ab}}$ \\ aUtrecht School of Economics \\ Utrecht University \\ ${ }^{\text {b}}$ Dutch Central Bank \\ Amsterdam
}

September 2011

\begin{abstract}
Several attempts have been made in the economics literature to measure money laundering. However, the adequacy of these models is difficult to assess, as money laundering takes place secretly and, hence, goes unobserved. An exception is tradebased money laundering (TBML), a special form of trade abuse that has been discovered only recently. TBML refers to criminal proceeds that are transferred around the world using fake invoices that under- or overvalue imports and exports. This article is a first attempt to test well-known prototype models proposed by Walker and Unger to predict illicit money laundering flows and to apply traditional gravity models borrowed from international trade theory. To do so, we use a dataset of Zdanowicz of TBML flows from the US to 199 countries. Our test rejects the specifications of the Walker and Unger prototype models, at least for TBML. The traditional gravity model that we present here can indeed explain TBML flows worldwide in a plausible manner. An important determinant is licit trade, the mass in which TBML is hidden. Furthermore, our results suggest that criminals use TBML in order to escape the stricter anti money laundering regulations of financial markets.
\end{abstract}

Keywords: Money laundering, international trade, gravity model, Walker model.

JEL classification: C21, F10.

\section{Acknowledgements}

The views expressed in this article are personal and do not necessarily reflect those of DNB. We owe a debt of gratitude to John Walker and John Zdanowicz, who provided us with essential databases. The authors thank for helpful comments of the participants of the Advanced Public Sector Research Seminar at Utrecht University School of Economics on July 1, 2009, the XVIII International 'Tor Vergata' Conference on 'Money, banking and finance' in Rome on December 2-4, 2009, the Research Seminar of DNB on January 6, 2011, and the Research Seminar of the Tjalling C. Koopmans Research Institute (TKI) of Utrecht University School of Economics on March 21, 2011. 


\section{Introduction}

Money laundering aims at disguising the illicit origin of money or other assets. The Chicago gangster Al Capone transformed illegal alcohol proceeds during times of the American prohibition into revenues from his laundry business, which gave the disguising process its name. Money laundering can take many forms: transferring criminal proceeds from one bank account to another repeatedly over the globe until its origin is untraceable, pretending to have won money through gambling, or using fake export and import bills to ship criminal proceeds outside or into a country.

The 9/11 terrorist attack in 2001 has enforced the US's sensitivity to illegal money flows, as authorities presume that such money transfers support international terrorist and criminal activities. Today financial transactions between the US and the rest of the world are closely monitored: banks have to report suspicious transactions and have to fulfill customer due diligence rules. However, Unger and den Hertog (2011) claim that similar to water which always finds its way, criminals also find new ways to escape anti money laundering regulation. Zdanowicz (2004b) sees trade as one important 'backdoor' for launderers, who can use fake invoicing of exports and imports and other forms of trade-based money laundering (TBML) to disguise illicit money flows. According to Zdanowicz, these new forms of abusing trade for laundering have not yet been addressed properly by the regulatory authorities.

TBML is a relatively unknown form of crime that is used to let illicit money pass borders unnoticed.

The Financial Action Task Force (2006) 'concludes that trade-based money laundering represents an important channel of criminal activity and, given the growth of world trade, an increasingly important money laundering and terrorist financing vulnerability. Moreover, as the standards applied to other money laundering techniques become increasingly effective, the use of trade-based money laundering can be expected to become increasingly attractive'. As it is a quite recently discovered form of crime, not much research on TBML is yet available. Zdanowicz (2004a) estimates the amount of trade-related dirty money flows to and from the largest trading country in the world, the US to amount to about one fifth of US trade. He has created the only available dataset revealing an indication of the volume of this type of criminal activity. ${ }^{1}$ To illustrate the dataset of Zdanowicz, Table 1 shows the top 10 countries in terms of incoming and outgoing TBML, in absolute and relative size.

Baker (2005) makes clear that laundering is not only a US concern, but especially detrimental for developing countries. According to his findings for every dollar sent to developing countries for

\footnotetext{
${ }^{1}$ Lately, his method also has been applied by the Joint Research Center of the European Commission in Italy, to study TBML in Austria, Belgium and the Netherlands, but the results have not been published. Detailed data for individual Dutch transactions, similar to those of Zdanowicz, are not passed on for scientific research, because the Dutch customs claims that they would violate privacy protected under the Dutch Law.
} 
development aid, ten dollars flow back to developed countries in the form of money laundering and illicit capital flight. That trade can enhance poverty in developing countries is an issue heavily discussed in the literature (e.g. Bené et al., 2010). Still lacking in this debate is the extent to which trade can be abused by criminals and tax evaders for money laundering purposes.

Table 1. Top 10 countries with trade-based money laundering from and to the US, in absolute and relative terms (2004)

\begin{tabular}{|c|c|c|c|c|c|c|c|c|}
\hline & \multirow{2}{*}{\multicolumn{2}{|c|}{$\begin{array}{l}\text { TBML out of US } \\
\text { in billions of US dollars }\end{array}$}} & \multicolumn{2}{|l|}{ TBML into US } & \multicolumn{2}{|l|}{ TBML out of US } & \multicolumn{2}{|l|}{ TBML into US } \\
\hline & & & & & as percentage of trade & & & \\
\hline 1 & Canada & 18.3 & Japan & 25.6 & Azerbaijan & 269 & Barbados & 26 \\
\hline 2 & Japan & 14.1 & Germany & 25.5 & Serbia \& Montenegro & 72 & San Marino & 25 \\
\hline 3 & China & 13.8 & Canada & 21.6 & Iran & 70 & Italy & 24 \\
\hline 4 & Mexico & 13.0 & China & 20.3 & Cuba & 62 & Germany & 23 \\
\hline 5 & Germany & 11.8 & UK & 16.2 & Kazakhstan & 35 & Monaco & 23 \\
\hline 6 & UK & 10.1 & Mexico & 14.7 & Bulgaria & 34 & Switzerland & 23 \\
\hline 7 & S Korea & 7.2 & France & 9.6 & Estonia & 32 & $\mathrm{UK}$ & 20 \\
\hline 8 & France & 5.5 & Italy & 9.4 & Denmark & 31 & Austria & 19 \\
\hline 9 & Taiwan & 4.8 & S Korea & 7.7 & Barbados & 26 & France & 18 \\
\hline 10 & Singapore & 4.3 & Taiwan & 6.4 & Philippines & 24 & Portugal & 17 \\
\hline
\end{tabular}

Source: dataset of Zdanowicz. The two lists in the left-hand panel show that the major trading partners of the US also have the most TBML with the US, but the two lists on the right hand reveal that in the rankings in relative terms other countries show up. The exports to Azerbaijan are so much undervalued, that the illegal money flow outnumbers the total trade data reported by a factor 2.7. Barbados is the only country that shows up in the top 10 of both outgoing and incoming TBML countries (measured as percentage of trade).

Since the introduction of anti-money laundering policy, high demand exists for estimates of money laundering to justify the burden that is put on public and private entities in charge of chasing dirty money. Walker (1995), Schneider (2008), Unger (2007), and Bagella et al. (2009) estimate the amount of money laundering based on an economic or econometric model. Walker (1995) was the first to propose a prototype model to estimate money laundering worldwide. His so-called Walker model is based on the well-known gravity model, which is quite popular in trade economics (Walker and Unger, 2009; Brakman and Van Bergeijk, 2010). This gravity-style model describes the geographical allocation of proceeds of crime, which need to be laundered to cover their criminal origin. The share of proceeds transferred from country A to country B depends on the 'attractiveness' of country B and the distance between the two countries. Unger (2007) revived the model for the Netherlands, by updating it and refining the distance indicator. However, due to lack of observations of money laundering, the weights or parameters of the attractiveness factors in Walker's model were never based on statistical estimates, but only plugged in with values of an inspirational guess. Although the outcome of the prototype model seems reliable when compared with other estimations (Walker and Unger, 2009), the actual specification of the model was never tested. So, the question that is still open is whether a gravity type equation can properly explain bilateral money laundering flows.

The outline of this paper is as follows. Section 2 introduces the traditional gravity model and explains how variants on this model are used to estimate world-wide money laundering flows. Section 3 
describes Zdanowicz's dataset on TBML, investigates the relationship between these TBML flows and licit trade and introduces the variables used in the literature to predict money laundering. Section 4 tests the relevance of the prototype models of Walker and Unger for TBML. Section 5 presents a traditional gravity model to explain TBML. The final section draws conclusions.

\section{The traditional gravity model}

For over decades the gravity model has been successfully applied to flows of the most widely varying types, such as migration, buyers distributed across shopping centers, recreational traffic, commuting, patient flows to hospitals and interregional as well as international trade. The model is inspired by Newton's universal law of gravity, which states that the attraction between two objects depends on the mass of these objects and (the inverse of) their squared mutual distance, apart from a constant. The model specifies that a flow from origin $i$ to destination $j$ is determined by supply conditions at the origin, by demand conditions at the destination and by stimulating or restraining forces relating to the specific flow between $i$ and $j$. In a context of international trade the traditional gravity model usually has the following form:

$$
X_{i, j}=\beta_{0} Y_{i}^{\beta_{1}} N_{i}^{\beta_{2}} Y_{j}^{\beta_{3}} N_{j}^{\beta_{4}} D_{i, j}^{\beta_{5}} P_{i, j}^{\beta_{6}}
$$

where $X_{i, j}$ is the value of trade between countries $i$ and $j, Y_{k}$ is the Gross Domestic Product (GDP) of country $k, N_{k}$ is the size of the population of country $k$, and $D_{i, j}$ and $P_{i, j}$ denote the distance between countries $i$ and $j$ and a possible special preference relationship, respectively. The gravity model of bilateral trade has become the workhorse of applied international economics (Eichengreen and Irwin, 1998) and has been used in any number of contexts. ${ }^{2}$ Some authors assume that the size of the population has no impact, thus $\beta_{2}=\beta_{4}=0$, which renders the resemblance to Newton's Law of Gravity even more obvious. ${ }^{3}$

The empirical results obtained with the model have always been judged as very good. Deardorff (1998) argues that the model is sensible, intuitive and hard to avoid as a reduced theoretical model to explain bilateral trade. Yet the gravity model has some imperfections. One is the absence of a cogent derivation of the model, based on economic theory. Several authors have tried to provide the model with such a theoretical basis, using models of imperfect competition and product differentiation, notably Anderson (1979), Bergstrand (1985), Helpman and Krugman (1985), Bikker (1987, 2010), and Anderson and Van Wincoop (2003), whereas Deardorff (1998) proves that the model is also consistent with the Heckscher-Ohlin trade theory under perfect competition. None of these derivations

\footnotetext{
${ }^{2}$ Linders (2006) finds 200 studies (actually a sample from a much larger set), and provides a selection in his Table 3.1. For an overview, see Anderson and Van Wincoop (2004).

${ }^{3}$ E.g. Tinbergen (1962), Pöyhönen (1963a, 1963b), Pulliainen (1963), and Bergstrand (1985).
} 
generate the gravity model exactly as formulated in Equation (1). ${ }^{4}$ This equation could only be approximated under a number of restrictive and unrealistic assumptions, as has been made clear by Bergstrand (1985). This is due to the absence of substitution in the basic gravity model of Equation (1). Substitution can be made plausible by an example from economic integration: the accession of Estonia to the European Union (EU) in 2004 has led to additional imports by other EU countries of wood, wood products and paper (the major export products of Estonia) - that is, gross trade creation. However, EU imports of wood products from other countries declined. This decline - trade diversion is not described by the basic gravity model. Bergstrand (1985), Bikker (1987, 2010), Anderson and Van Wincoop (2003) and Redding and Scott (2003) extend the basic model with a substitution structure.

As TBML is closely related to trade flows, this paper will use the successful basic gravity model Equation (1), extended with additional explanatory variables - for TBML flows stemming from the US.

\subsection{A gravity model for money laundering}

In earlier years, Walker (1995) already recognizes that the gravity model may be useful in order to explain laundered money flows between countries. His prototype model for money laundering assumes that the share of proceeds from crime generated in country $i$ and sent to country $j$ depends on both the mass and 'attractiveness' of country $j$, and the distance between the two countries:

$$
F_{i j} / \sum_{i} F_{i, j}=\left(\left(\text { GNP }_{j} / \text { Population }_{j}\right) * \text { Attractiveness }_{j}\right) /\left(\text { Distance }_{i, j}^{2}\right.
$$

$F_{i j}$ is the amount of money laundering flowing from country $i$ to country $j$. In this model, the flows are expressed into shares of countries $j$ in the total outflows of country $i$ (by dividing the flows by $\Sigma_{i} F_{i j}$, the total amount of money to be laundered in country $i$ ). If we compare this equation to Equation (1), we see that Mass of $j$ is represented by $\mathrm{GNP}_{j} / \mathrm{Population}_{j} \times$ Attractiveness $_{j}$ and Mass of $i$ by $\Sigma_{i} F_{i j}{ }^{5}$ By the way, the interpretation of Equation (2) as gravity model is not from Walker himself but from Unger (2007). The first mass factor is per capita income, based on Gross National Product (GNP). The second is attractiveness, which is put forward as the sum of a number of weighted factors contributing to the quality of country $j$ for money laundering:

$$
\text { Attractiveness }_{j}=3 B S_{j}+G A_{j}+\text { Swift }_{j}-3 C F_{j}-C R_{j}+15
$$

\footnotetext{
${ }^{4}$ The most restrictive theoretical model of Anderson, Bergstrand, as well as Helpman and Krugman, is a gravity model with only GDPs as determinants. A less restrictive model has a different functional form (Anderson, Equation (16) or additional determinants (Bergstrand, Equation (14)).

${ }^{5}$ Note that Mass of $i$ is not exactly equal to $\Sigma_{i} F_{i j}$.
} 
where $B S$ is banking secrecy and $G A$ government attitude, Swift indicates countries with financial institutions that are member of Swift, $C F$ refers to conflict and $C R$ stands for corruption. ${ }^{6}$ This equation became well known in the money laundering field as the Walker equation and has been used to estimate money laundering flows (see e.g. Walker, 1995, and Walker, 1999). The underlying idea is that since the gravity model can predict trade flows and many other flows so well, it may also be able to predict money laundering flows. Fundamental critiques on Walker's model concern its ad hoc nature and the fact that it is not empirically testable, in fact because data on money laundering flows $F_{i j}$ are lacking.

Unger (2007) modifies the Walker equation by using the distance between the countries in the attractiveness factor, instead of its square. Empirical findings are that most gravity equations for trade come up with an estimate of around -0.9 (Helliwell, 2000). Unger (2007) also redefines physical distance by including three 'cultural' factors: sharing a common language, having colonial ties or being major trading partners of each other. Moreover, in the attractiveness index she includes the 'membership of the Egmont group', a cooperation of national Financial Intelligence Units fighting money laundering, and 'financial sector size' (measured as deposits), as proxies for the fact that extended financial markets make it easier to launder criminal proceeds. ${ }^{7}$

\section{The data}

In order to apply the gravity model to TBML flows, we use data for 199 countries, stemming from four different sources. The first dataset is from CEPII (www.cepii.fr), a French research center in international economics, which provides a database with determinants for gravity equations of trade flows. These variables are Border dummy (with value one when two countries share a border), Common language dummy (one when two countries have the same language), Colony dummy (one when one of the two countries was a colony of the other) and Distance (measured in kilometers 'as the crow flies' between the countries' economically most important cities). The second database on factors determining money laundering has been collected by John Walker for the estimation of his model (Walker, 1999). The attractiveness variables are Corruption (a simplified scale based on the Transparency international index of 1996, meaning that countries with a low score have a low

\footnotetext{
${ }^{6}$ Note that corruption has a negative impact on laundering. Walker assumes that criminals do not like (excessively) corrupt countries, because corruption increases costs of laundering due to necessary side payments and bribes. On the other hand, a very low corruption level might make it difficult to find facilitators for laundering, increasing the transaction costs of laundering. The corruption-laundering literature is ambiguous about the sign. Chaikin and Sharman (2009) give an overview over the various theoretical links between corruption and money laundering. Dreher and Schneider (2010) find this ambiguity for the shadow economy also empirically: corruption reduces the shadow economy in high-income countries, but increases it in low-income countries.

${ }^{7}$ Further, she replaces GNP by GDP.
} 
corruption level), Swift member (a dummy variable with 1 for countries with financial institutions that are member ), Government attitude (a score for the attitude of a government towards money laundering, going up with tolerance), Conflict (a score for a country's conflict status, with 1 for peace and 4 for a heavy conflict) and Bank secrecy (the score goes up with secrecy). ${ }^{8}$ Tables A.1-2 in Appendix 1 provide greater detail.

We also use the variables defined and described in Unger (2007). New attractiveness variables are Egmont Group, a dummy with value 1 for members, and Financial sector size, which measures the relative size of the financial sector as Financial Deposits (demand, time and saving deposits) as a share of GDP. Moreover, she replaces the physical distance for a measure of cultural and physical distance. ${ }^{9}$ The other variables are roughly identical to those of Walker. Roughly, because the data have been constructed and for some variables scaled slightly differently, see Table A.2 for details. ${ }^{10}$ The last dataset consists of the 2004 estimates on TBML flows from the US by Zdanowicz. His dataset also provides the trade data (imports and exports) for the US in millions of dollars. ${ }^{11}$

\subsection{Identifying trade-based money laundering}

Zdanowicz (2009b) has scrutinized the US Merchandise trade database for suspicious transactions. It contains all import and export transactions data of the US with the rest of the world starting in 2004. He uses ten-digit product codes, ${ }^{12}$ hence very detailed product specifications, and assumes that international trade transactions involving abnormally high or low prices, indicate money laundering ${ }^{13}$ (for the thresholds, see Zdanowicz, 2009b). Examples are bottles of ketchup for 50 dollars, a football for 3000 dollars, and a Gucci watch worth US\$100,000 dollar noted as a US\$ 50 Swatch on the import bill. Table 2 presents aggregated estimates of TBML by origin.

In 2004, an amount of US\$ 175 billion entered the US by means of undervalued imports, see Table 2. In that case, profits are generated in the US (that is, white money has been created) by selling

\footnotetext{
${ }^{8}$ The first two variables are from public sources, while the last three variables are from an unpublished report on potential international security threats to Australia, provided by the Australian Office of Strategic Crime Assessments.

${ }^{9}$ For a description of how this cultural and physical distance is constructed, see Unger (2007), page 78.

${ }^{10}$ We use Walker's definitions for the test of his model and for our traditional gravity and Unger's definitions for the test of her model.

${ }^{11}$ Tables A.1-2 in Appendix 1 provides descriptive statistics of these variables.

${ }^{12}$ Transactions are classified under approximately 8,000 different products. Every item that is exported is assigned a unique 10-digit identification code. The Harmonization Code System (HS-Code) is a system of progressively more specific identifiers for a commodity. For example, concentrated frozen apple juice is assigned a 10-digit identifier. This number is an aggregate of a series of codes starting with a broad category assigned a 2-digit identifier described as Preparations of Vegetables, Fruit, Nuts, etc. It is then assigned a 4-digit identifier described as fruit juices and vegetable juices, etc. The 6-digit identifier is described as apple juice. Information from http://exim.indiamart.com/product-classification/ on May 9, 2011

${ }^{13}$ These abnormal prices can also indicate typographical errors or transfer pricing by multinational firms. The typographical errors will not affect our results as long as they are randomly distributed, since we correct for the size of trade in our final estimation model. Illegal transfer pricing may be included in the TBML estimates of Zdanowicz.
} 
expensive but fraudulently low-priced imported goods in the US. US\$ 48 billion flew into the US by means of overvalued exports. In that case, profits are generated in the US by selling cheap but fakely high-priced US goods to foreign clients. US\$ 56 billion left the US by means of overvalued imports and 112 billion dollar by undervalued exports. In these cases profits are similarly generated outside the US, respectively by importing overvalued goods and exporting undervalued goods. In total TBML amounts to 391 billion US\$, or 17 percent of total US trade with other countries in 2004.

Table 2. Trade-based money laundering estimates from Zdanowicz by origin in 2004 (billion US\$)

\begin{tabular}{lccl}
\hline & Imports into the US & Exports from the US & Combination \\
\hline Undervalued & 175 TBML into US & 112 TBML out of US & Swap type 1 \\
Overvalued & 56 TBML out of US & 48 TBML into US & Swap type 2 \\
\hline
\end{tabular}

Source: own calculation based on Zdanowicz (2004a).

TBML flows may also be symmetric. Two partners in crime who both want to launder their criminal money, may set up a TBML swap, see the first row of Table 2. They sent undervalued trading goods to each other, both incurring effort and cost but also obtaining laundered money. An additional advantage may be that they both have profits as well as (tax-deductible) losses, so that they can avoid tax levies on their 'white' profits. An alternative swap consists of exchanging overvalued goods (swap type 2 in Table 2). This swap is even less bothersome as no need exists to sell (undervalued) goods and the overvalued goods may be disposed. Since these swaps do not transfer money internationally, they are less suited for sending terrorist money. Swaps may also be executed within one country. For international remittance of funds a single TBML transaction will do, or a (cross) diagonal combination of transactions in Table 2.

\subsection{Relationship between licit trade flows and $T B M L$}

Our TBML dataset allows us to investigate the relationship between licit trade flows and TBML. We refer to licit trade when we consider trade as reported in the usual trade statistics. Of course, these flows are polluted by TBML where that occurs. The basic question here is whether TBML is more or less proportional to trade flows, or whether it is distinct from licit trade. We use the Lorenz curve, manifoldly used to measure income inequality, to visualize the relationship between trade and TBML. The calculations behind the Lorenz curves are explained in Appendix 2.

The diagonal in the Lorenz curve diagram reflects TBML which is strictly proportional to licit trade, which is the case if the respective ratios are unity. The values for the ratios determine the positions in the Lorenz curve diagrams: countries with a value below 1 will be located on the bottom-left hand. If the ratio is 1 , the country will be at the point of the Lorenz curve where it runs parallel with the diagonal (so with a slope of 1). Finally, countries with ratios higher than 1 will be located on the upper-right hand corner. Figure 1 (first panel) ranks countries according to the ratio of their share of 
Graph 1. Lorentz curves of trade-based money laundering versus US imports and exports (2004)

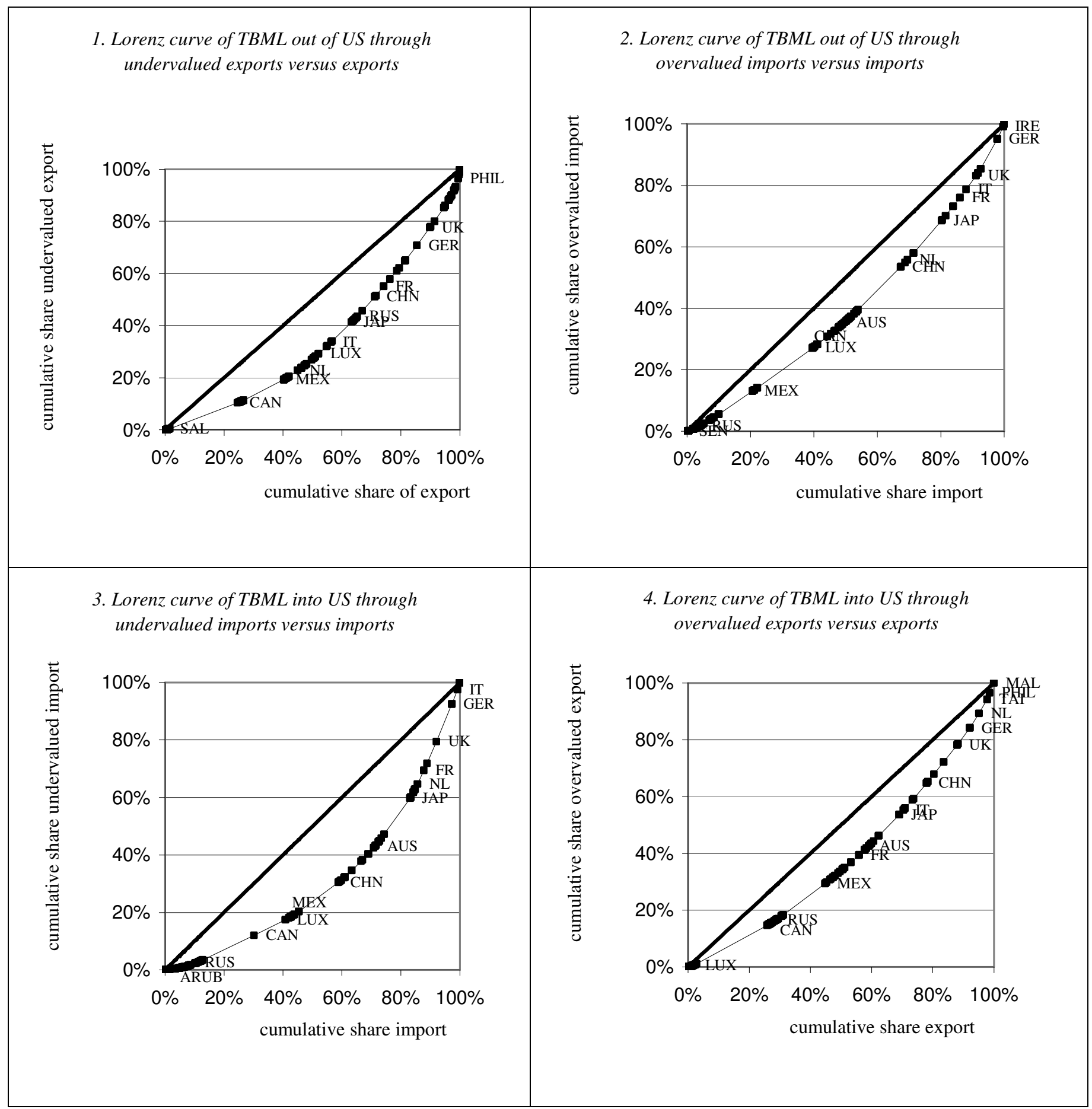

Source: Own calculation based on Zdanowicz (2004a).

undervalued exports divided by their share of total exports. The horizontal axis measures the cumulative share of exports, while the vertical axis measures the cumulative share of TBML by means of undervalued exports. Canada with a share of 23 percent in US exports and a 9.9 percent share of total US TBML outflow through undervalued exports has a ratio of 0.43 , hence relatively little TBML. 
Japan and Italy take intermediate positions. At the upper-far right end we find the Philippines, with a ratio of 3.52, and Denmark (not shown) with a ratio of 4.95 (see also Table A.5 in Appendix 1).

The Lorenz curves show that UK, Germany, France, Italy and also Malaysia always have overproportional shares, while Canada and Mexico always have underproportional shares of tradebased money laundering. Other countries have sometimes over proportional and sometimes underproportional shares. The overall picture that emerges is that TBML flows seem to be strongly related to trade flows. This is shown by the rather 'flat bellies' of all the Lorenz curves. What we see is that the actual Lorenz curves, especially for overvalued imports (Figure 2, upper right panel) and overvalued exports (Figure 4, lower right panel), are very close to the diagonal. To conclude, this result suggests that overall trade and TBML are strongly related. Given the absence of clear theoretical principles explaining TBML flows and the fact that in the past licit trade flows have been successfully explained by gravity models, the next sections will investigate the explanatory power of the gravity model for TBML. If we go into greater detail, we observe that countries with a dubious reputation such as Barbados, Liberia, Monaco, Philippines and Switzerland have overproportional TBML by a factor of at least three, indicating that TBML is not just a 'normal' part of licit trade (see Table A.5, the FATF black list and the OECD grey list).

\section{Testing the Walker model for TBML}

We apply the prototype model proposed by Walker (1995) on TBML to test whether his specification is supported by our data. Therefore, we replace in Equation (2) the share of country $j$ for money laundering from country $i$ ( $F_{i j} / \sum_{i} F_{i, j}$ ) by the share of country $j$ for TBML from the US

$$
\begin{aligned}
& \left(T B M L_{i j} / \sum_{j}^{n} T B M L_{i j}\right)^{: 14} \\
& T B M L_{i j} / \sum_{j}^{n} T B M L_{i j}=\left(G D P_{j} / \text { Population }_{j}\right) *\left(\beta_{1} B S_{j}+\beta_{2} G A_{j}+\beta_{3} S_{w i f t}+\beta_{4} C F_{j}+\beta_{5} C R_{j}+\beta_{6}\right) / D_{i j}^{\beta_{7}}
\end{aligned}
$$

Table 3 presents the estimation results of Equation (3). Since the model is nonlinear in its parameters, we use the Nonlinear Least Squares (NLS) estimation procedure. Starting values for the model parameters, as required in the NLS's iterative numerical estimation procedure, stem from Walker

\footnotetext{
${ }^{14}$ Note that our application of this Walker model differs from the standard gravity model for trade in the sense that we have data of flows to or from the US only, while normally flows from many origin countries to many destination countries are considered. Since in the Walker model only the characteristics of the destination country $j$ matter, we use only the flows of TBML from the US to all other countries in the world. We cannot use the TBML flows to the US, because these flows all have the same destination country $j$ (the US) and therefore have no variation in the model of Equation 3.
} 
(1995). Column 1 gives the initial Walker values, while Column 2 gives the estimated NLS coefficients, which differ greatly from the Walker values for money laundering, where, for some variables, even the sign changed. The only coefficient that is significantly different from zero is the distance coefficient. With an estimated value of 0.614 (significant at the $1 \%$ level), this coefficient is however not close to the value of 2, as suggested by Walker (and as in Newton's gravity law). The model is able to explain $43 \%$ of the variation in the share of total TBML across countries. ${ }^{15}$

Table 3. Testing the Walker (1995) model using estimates of trade-based money laundering flows out of the US (2004)

\begin{tabular}{|c|c|c|c|c|c|}
\hline & \multirow{2}{*}{$\begin{array}{l}\text { Walker's } \\
\text { values for } \mathbf{M L} \\
\text { Parameters } \alpha_{i}\end{array}$} & \multicolumn{4}{|c|}{ NLS estimates of Equation (3) for TBML } \\
\hline & & Coefficients $\beta_{i}$ & $\begin{array}{l}\text { Standard } \\
\text { deviation }\end{array}$ & $\begin{array}{l}t \text {-test } \\
H_{0}: \beta_{i}=0\end{array}$ & $\begin{array}{l}t \text {-test } \\
H_{0}: \beta_{i}=\alpha_{i}\end{array}$ \\
\hline Column & $(1)$ & (2) & $(3)$ & $(4)$ & $(5)$ \\
\hline Bank secrecy & 3 & -0.022 & 0.015 & -1.51 & -201.47 \\
\hline Government attitude & 1 & -0.037 & 0.024 & -1.52 & -43.21 \\
\hline Swift membership & 1 & 0.072 & 0.077 & 0.95 & -12.05 \\
\hline Conflict level & -3 & 0.110 & 0.090 & 1.23 & 34.56 \\
\hline Corruption level & -1 & -0.015 & 0.013 & -1.20 & 75.77 \\
\hline Distance to US & 2 & $* * * 0.614$ & 0.079 & 7.78 & -17.54 \\
\hline Constant & 15 & 0.052 & 0.074 & 0.71 & -202 \\
\hline Nr. of observations & & 199 & & & \\
\hline Adjusted $\mathrm{R}^{2}$ & & 42.7 & & & \\
\hline
\end{tabular}

Note: ${ }^{* * *}$ indicates significance at the $1 \%$ level.

To test whether the estimates differ significantly from the suggested values in Walker (1995), we assume that the errors are distributed normally and use the coefficient standard errors in Column 3 to compute $t$-values of the estimates in Column 5. Column 5 tests for each model variable the null hypothesis that the true beta coefficient is equal to the Walker values (denoted by $\alpha_{i}$ ). For each of the model parameters, we reject the Walker value. We conclude here the Walker (1995) model is unable to explain the estimates of TBML from the US to all other countries in the world in a satisfactory manner. ${ }^{16}$

\subsection{Testing the modified Walker model of Unger}

As a next step we use our dataset to evaluate the modified Walker model for money laundering suggested by Unger (2007), which includes cultural factors for the constructed measure of cultural and physical distance $(C P D)$ and two more variables for the attractiveness: size of the financial sector and Membership of the Egmont group. The equation that will be estimated is specified as:

\footnotetext{
${ }^{15}$ A caveat is that Walker specifies his model for money laundering while we test the model using data of only one type of money laundering.

${ }^{16}$ Please note that the failure of the Walker model to explain TBML well could come from the fact that the parameters of the Walker model have never been tested but resulted from an inspirational guess or because money laundering in general is explained significantly differently than TBML.
} 


$$
\begin{aligned}
& T_{B M L_{i j}} / \sum_{j}^{n} T B M L_{i j}=\left(G D P_{j} / \text { Population }_{j}\right) *\left(\beta_{1} B S_{j}+\beta_{2} G A_{j}+\beta_{3} \text { Swift }_{j}+\beta_{4} C F_{j}+\beta_{5} C R_{j}\right. \\
& \left.+\beta_{6} \text { Egmont }_{j}+\beta_{7} F D_{j}+\beta_{8}\right) / C P D_{i j}^{\beta_{9}}
\end{aligned}
$$

Table 4 presents the estimates of Equation (4). The parameter values in Column 1 are suggested by Unger (2007). Table 4 shows that - similar to the testing of the Walker specification - all coefficients are insignificant, except the coefficient of the cultural and physical distance (2.85), which is significantly at the $1 \%$ level. Column 5 presents the $t$-test values on the null hypothesis that the Unger parameter values are 'true'. The results make clear that all variables are significantly different from what is suggested by Unger (2007). We conclude that we hardly find any empirical underpinning for the prototype models of Walker (1995) and Unger (2007), except that one of the key variables of the gravity model - distance - is apparently essential.

Table 4. Testing the modified Walker model of Unger (2007) applied to trade-based money laundering (2004)

\begin{tabular}{lrrrrr}
\hline & $\begin{array}{l}\text { Unger's values } \\
\text { for ML }\end{array}$ & \multicolumn{2}{l}{ NLS estimates of Equation (4) for TBML } \\
\cline { 2 - 6 } & Parameters $\alpha_{i}$ & Coefficients $\beta_{i}$ & $\begin{array}{l}\text { Standard } \\
\text { deviation }\end{array}$ & $\begin{array}{r}t \text {-test } \\
H_{0}: \beta_{i}=0\end{array}$ & $\begin{array}{r}t \text {-test } \\
H_{0}: \beta_{i}=\alpha_{i}\end{array}$ \\
\hline Column & $(1)$ & $(2)$ & $(3)$ & $(4)$ & $(5)$ \\
\hline Bank secrecy & 3 & -0.056 & 0.039 & -1.45 & -78.36 \\
Government attitude & 1 & -0.082 & 0.054 & -1.51 & -20.04 \\
Swift membership & 1 & 0.014 & 0.117 & 0.12 & -8.43 \\
Conflict level & -3 & 0.021 & 0.019 & 1.10 & 159.00 \\
Corruption level & -1 & 0.023 & 0.025 & 0.92 & 40.92 \\
Egmont group & 1 & 0.074 & 0.065 & 1.14 & -14.25 \\
Financial deposits & 1 & -0.002 & 0.009 & -0.28 & -111.33 \\
Physical and cultural distance & 1 & $* * * 2.848$ & 0.327 & 8.71 & 5.66 \\
Constant & 10 & 0.161 & 0.147 & 1.09 & -66.93 \\
Nr. of observations & & 199 & & & \\
Adjusted R ${ }^{2}$ & & 42.8 & & & \\
\hline
\end{tabular}

Note: ${ }^{* * *}$ indicates significance at the $1 \%$ level

\section{A gravity model for trade-based money laundering}

Since the Walker model and the adjusted Walker model do not seem to explain TBML well, we use a standard gravity model -see Equation (1) - expanded by the variables used in the attractiveness indicators of the (adjusted) Walker model to explain TBML. ${ }^{17}$ This model has a straightforward

\footnotetext{
${ }^{17}$ Our dataset consists of estimations of TBML from the US to the rest of the world only, while normal gravity models use data of flows between all origins and destinations. To show that it is possible to estimate a gravity equation with data on only a part of the flows, we estimated a standard gravity equation for trade with our dataset in Appendix 3.
} 
loglinear nature instead of the combination of additive and multiplicative variables as in the prototype models of Walker and Unger.

Table 5. Trade-based money laundering gravity model for US outflow (2004)

\begin{tabular}{|c|c|c|c|c|c|c|}
\hline & \multicolumn{4}{|c|}{ Gravity model for TBML } & \multirow{2}{*}{\multicolumn{2}{|c|}{$\frac{\text { Best fit model (AIC) }}{\text { Structural model }}$}} \\
\hline & \multicolumn{2}{|c|}{ Structural model } & \multicolumn{2}{|c|}{ Reduced form model } & & \\
\hline & Coeff. & St. dev. & Coeff. & St. dev. & Coeff. & St. dev. \\
\hline Trade & $* * * 1.02$ & 0.09 & & & $* * * 1.03$ & 0.09 \\
\hline GDP & $* 0.22$ & 0.18 & $* * * 0.85$ & 0.28 & $* * 0.14$ & 0.07 \\
\hline Population & -0.05 & 0.10 & 0.06 & 0.24 & & \\
\hline Border dummy & $* * *-2.60$ & 0.64 & -0.13 & 1.61 & $* * *-2.53$ & 0.57 \\
\hline Common language & 0.33 & 0.35 & 0.42 & 0.53 & & \\
\hline Colonial background & -0.20 & 0.61 & 0.66 & 1.14 & & \\
\hline Swift membership & -0.15 & 1.20 & 0.00 & 1.69 & & \\
\hline Egmont membership & 0.48 & 0.33 & $* * 1.42$ & 0.59 & $* * 0.59$ & 0.28 \\
\hline Financial deposits & -0.05 & 0.32 & $* 1.05$ & 0.63 & & \\
\hline Corruption level & 0.20 & 0.28 & -0.14 & 0.57 & & \\
\hline Bank secrecy & 0.11 & 0.19 & 0.40 & 0.39 & & \\
\hline Government attitude & $*-0.44$ & 0.25 & -0.64 & 0.50 & $*_{-} *_{-0.39}$ & 0.19 \\
\hline Conflict & $* 0.31$ & 0.19 & 0.24 & 0.31 & 0.29 & 0.19 \\
\hline Distance & $*_{-0.34}$ & 0.19 & $* * *-1.10$ & 0.31 & $* * *-0.34$ & 0.14 \\
\hline Constant & $*_{*} *_{-5} .26$ & 2.24 & 5.42 & 4.53 & $* *-3.88$ & 1.54 \\
\hline Nr. of observations & 199 & & 199 & & 199 & \\
\hline Adjusted $\mathrm{R}^{2}$ & 88.2 & & 66.9 & & 88.5 & \\
\hline
\end{tabular}

Table 5 presents the results of the gravity model for TBML flows. One of the driving factors of TBML is licit trade itself: the larger the trade flow, the larger opportunities for fraud. Therefore, in the TBML model at the left-hand side of Table 5 trade has been added as explanatory variable. We call this the 'structural model', as it explains the impact of trade separately from the other explanatory variables. The next paragraph will discuss the 'reduced form model'. We consider this to be the best specification of a TBML gravity equation, which, apart from the different functional form, is in fact a slight extension of the modified Walker model: we add trade and a border dummy as explanatory factors. Estimation results confirm that trade is an important determinant of TBML, as its coefficient is significant at the $1 \%$ level. The coefficient of around 1 indicates proportionality between trade en TBML, in line with the Lorentz curve analysis in Section 3.2. Except for trade and the border dummy (which in this case is basically a dummy for US trade with Canada and Mexico), many independent variables are insignificant or only significant at the $10 \%$ level. Therefore, we use Akaike's Information Criterion (AIC) to search for the best fit model specification. The model with the lowest AIC is presented at the right hand side of Table 5. The AIC indicates to drop Population, Common Language, Colonial Background, Swift membership, Financial deposits, Corruption level and Bank secrecy. In this leaner specification, GDP, Egmont Membership, Government Attitude and Distance become significant at a 5\% level. TBML flows can best be explained by GDP (which represents the mass of

\footnotetext{
${ }^{18}$ Note that we use only one variable for categorical variables (as explained in Table A.2 in Appendix 1), instead of a dummy for each category. Using a dummy for each category does not alter the results significantly.
} 
the countries), trade (which represents the mass of the flow in which TBML is hidden), distance (as is standard in gravity models, corrected for border countries) and two anti-money laundering policy variables (Egmont-membership and Government attitude). Surprisingly, the two anti-money laundering policy variables have the opposite sign of what was expected by Walker (1995) and Unger (2007). Membership of Egmont, i.e. a cooperation agreement between countries to fight money laundering together, leads to more TBML and countries with a government that have a hostile attitude towards money laundering have more TBML than those with a more tolerant attitude. These relations can probably best be explained by the fact that TBML has been discovered quite recently, while the anti-money laundering policies at the moment are targeted almost completely on the traditional form of money laundering in the financial system. Our results suggest that money launderers use TBML as an alternative for traditional money laundering when the country they send their money to is fighting (the traditional form of) money laundering intensively. An alternative explanation is that countries which face more money laundering are more eager to undertake adequate actions to combat it.

Finally, the middle panel of Table 5 presents the estimation results of the 'reduced form model'. Here, the underlying classical gravity model for international trade - with GDP, Population and Distance as its main determinants - is as if substituted in the 'structural model'. As a result, TBML is explained directly from the traditional gravity variables GDP, Population and Distance as well as the typical money laundering variables. As common in trade models the GDP coefficient does not differ significantly from 1 and the distance measure coefficient does not deviate significantly from -1.

Remarkably, in this specification, the Egmont membership coefficient is significantly at the 5\% level, while the Financial deposits coefficient is significantly at the $10 \%$ level. However, the goodness-of-fit measure (adjusted $\mathrm{R}^{2}$ ) makes clear that this reduced form model is inferior to the structural model $(69.2 \%$ versus $88.2 \%)$. Apparently, the (complete) trade data are of great importance in explaining TBML. ${ }^{19}$

\section{Conclusion}

Combating money laundering is important for society. However, an evaluation of the effects of anti money laundering policies is hampered by an enormous lack of data. That has motivated Walker and Unger to propose a prototype model for money laundering which has characteristics of the traditional gravity model. The model parameters were based on guess estimates. We use a dataset of Zdanowicz on trade-based-money laundering and find that TBML is indeed much more frequent in relative terms in US trade with countries which have a dubious status in terms of money laundering. With this dataset, we are able to test the Walker and Unger prototype models for money laundering when

\footnotetext{
${ }^{19}$ In the reduced form model only the model value of trade (exclusively of the residual or error term) while in the structural model the complete value (including the error term) is used.
} 
applied to TBML. Our conclusion is that these models perform badly for this subset of money laundering. We replace the functional form of the Walker model, which is a mix of linear and multiplicative variables, by a multiplicative standard gravity equation as frequently used for trade flows, and extend this model with explanatory variables from the Walker and Unger models. We are then able to explain the distribution of TBML between 199 countries and the US in a satisfactory manner. TBML appears to be highly related to licit trade, which permits this kind of money laundering to go unnoticed, as illicit proceeds hide in the large pool of licit exports and imports. Other explanatory variables are distance between the respective two countries, correction for bordered countries, GDP of the importing country, and whether the importing country fights money laundering. The latter is measured by membership of Egmont, i.e. a multilateral cooperation agreement to fight money laundering together, and by the attitude of the importing country towards money laundering. Hence, we can apply the traditional intuition of a gravity model - that is, explain a flow by two masses and the mutual distance - to TBML. One might expect that governments which agree to fight money laundering (through their Egmont Membership) and have a hostile attitude towards money laundering experience less TBML. However, our results suggest the opposite: countries, which have strict antimoney laundering regulation, experience more trade related money laundering. This may indicate that criminals have discovered a new way of laundering by using TBML to escape stricter anti-money laundering regulation of the financial sector.

\section{References}

Anderson, J.E. (1979) A theoretical foundation for the gravity equation, American Economic Review 69 106-116.

Anderson, J.E. and Van Wincoop, E. (2003) Gravity with gravitas: a solution to the border puzzle, American Economic Review 93, 170-192.

Anderson J.E. and Van Wincoop, E. (2004) Trade costs, Journal of Economic Literature 42, 691-751.

Bagella, M., F. Busato and A. Argentiero (2009) Money laundering in a microfounded dynamic model simulations for the US and the EU-15 Economies, Review of Law and Economics, 5, 879-902.

Baker, R. W. (2005) Capitalism's Achilles heel, dirty money and how to renew the free market system, John Wiley and Sons, Hoboken, New Jersey.

Bené C., Lawton R. and Alllison E.H. (2010), Trade matters in the fight against poverty. Narratives, perceptions, and (lack of) evidence in the case of fish trade in Africa, World Development 38 , 933-954.

Bergstrand, J.H. (1985) The gravity equation in international trade: some microeconomic foundations and empirical evidence. Review of Economics and Statistics 67, 471-481.

Bikker, J.A. (1987) An international trade flow model with substitution: an extension of the gravity model, Kyklos 40, 315-337. 
Bikker, J.A. (2010) An extended gravity model with substitution applied to international trade, in: Brakman, S., and P.A.G. van Bergeijk (eds), The gravity model in international trade: advances and applications, Cambridge University Press, 135-162.

Brakman, S., and P.A.G. van Bergeijk (eds), (2010) The gravity model in international trade: advances and applications, Cambridge University Press.

Deardorff, A.V. (1998) Determinants of bilateral trade: does gravity work in a neoclassical world? In J.A. Frenkel (ed.), The regionalization of the world economy. London, Chicago: Chicago University Press, 7-28.

Chaikin, D. and J.C. Sharman (2009) Corruption and money laundering: a symbiotic relationship, Palgrave Macmillan.

Dreher, A. and F. Schneider (2010) Corruption and the shadow economy: an empirical analysis, Public Choice 144, 215-238.

Eichengreen, B., and Irwin, D.A. (1998) The role of history in bilateral trade flows, in: J.A. Frankel (ed.), The regionalization of the world economy, 33-57, Chicago, University of Chicago Press.

FATF (2006) Trade-based money laundering, Financial Action Task Force, http://www.fatfgafi.org/dataoecd/60/25/37038272.pdf.

Helliwell, J.F. (2000) Language and trade, gravity modelling of trade flows and the role of language, Canadian Heritage, Canada. http://www.pch.gc.ca/progs/lo-ol/perspectives/english/explorer/ page_01.html

Helpman, E. and Krugman, P.R. (1985) Market structure and foreign trade: increasing returns, imperfect competition, and the international economy, Cambridge (USA).

Linders, G.J.M. (2006) Intangible barriers to trade; the impact of institutions, culture and distance on pattern of trade, Tinbergen Institute Research Series $n r .371$, Tinbergen Institute.

Pölyhönen, P. (1963a) A tentative model for the volume of trade between countries, Welwirtschaftliches Archiv 90, 93-100.

Pölyhönen, P. (1963b) Toward a general theory of international trade. Economiska Samfundets Tidskrift 16, 69-77.

Pulliainen, K. (1963) A world trade study: an econometric model of the pattern of the commodity flows of international trade in 1948-60, Economiska Samfundets Tijdskrift 16, 78-91

Redding, S. and P.K. Scott (2003) Distance, skill deepening and development: will peripheral countries ever get rich?, Journal of Development Economics 72, 515-541.

Schneider, F. (2008) money laundering and financial means of organized crime: some preliminary empirical findings, in: Global Business and Economics Review, Interscience Enterprises Ltd, 10 (3), 309-330.

Tinbergen, J. (1962) Shaping the world economy: suggestions for an international economic policy. Twentieth Century Fund, New York.

Unger, B. (2007) The scale and impacts of money laundering, Edward Elgar, Cheltenham, UK 
Unger, B. and J. den Hertog (2011) Water always finds its way - Identifying new forms of money laundering, Crime Law and Social Change (A Special Issue on Black and Gray Finance, edited by S. Hsu; to appear in December 2011).

Walker, J. (1995) Estimates of the extent of money laundering in and throughout Australia, report for the Australian Financial Intelligence Unit AUSTRAC.

Walker, J. (1999) How big is global money laundering?, Journal of Money Laundering Control 3, 2537.

Walker, J. and B. Unger (2009) Measuring global money laundering: the Walker gravity model, Review of Law \& Economics 5, 821-853.

Zdanowicz, J.S. (2004a) U.S. trade with the world and Al Qaeda watch list countries - 2001: An estimate of money moved out of and into the US due to suspicious pricing in international trade, http://business.fiu.edu/pdf/PrintJun2007/tfml.pdf.

Zdanowicz, J.S. (2004b) Who's watching our back door?, Business Accents, College of Business Administration magazine, Florida International University, Fall 2004, Volume 1, $26-29$.

Zdanowicz, J.S. (2009a) Money launderers wash billions through international trade, Miami Herald, May 11, 2009: http://www.miamiherald.com/154/story/1041027.html.

Zdanowicz, J.S. (2009b), Trade-based money laundering and terrorist financing, Review of Law and Economics 5, 855-878. 
Appendix 1. Descriptive statistics and greater details of trade-based money laundering data

Table A.1 Descriptive statistics of trade, TBML and explanatory variables of 200 countries (2004)

\begin{tabular}{|c|c|c|c|c|c|c|c|c|c|}
\hline & Unit & Mean & Sd & Median & $\mathrm{Nr}^{\mathrm{a}}$ & Min & Max & Skewness & Kurtosis \\
\hline Total TBML & US\$, logs & 17.65 & 3.41 & 17.64 & 200 & 8.33 & 24.41 & -0.16 & 2.52 \\
\hline TBML into the US & US\$, logs & 16.72 & 3.50 & 16.61 & 199 & 6.68 & 23.97 & -0.08 & 2.65 \\
\hline TBML out of the US & US\$, logs & 17.00 & 3.40 & 17.27 & 200 & 7.41 & 23.63 & -0.19 & 2.36 \\
\hline Trade & million US\$, logs & 6.39 & 2.68 & 6.16 & 200 & -2.32 & 13.00 & 0.04 & 2.76 \\
\hline GDP per capita & million US\$, logs & 9.85 & 2.57 & 10.02 & 199 & -1.35 & 15.69 & -0.52 & 3.96 \\
\hline Financial system deposits & $\begin{array}{l}\text { share of GDP, } \\
\text { logs }\end{array}$ & 0.29 & 0.30 & 0.23 & 199 & 0.00 & 2.17 & 1.89 & 10.09 \\
\hline Distance to US & $\mathrm{km}$ & 8.92 & 0.55 & 9.02 & 200 & 6.31 & 9.69 & -1.20 & 4.93 \\
\hline Corruption index (Walker) & & 3.83 & 0.98 & 4.00 & 200 & 1.00 & 4.93 & -1.15 & 3.69 \\
\hline
\end{tabular}

${ }^{a} \mathrm{Nr}$ stands for number of observations.

Table A.2 Descriptive statistics of the attractiveness term by Walker and Unger

\begin{tabular}{|c|c|c|c|}
\hline Walker data variables & $\mathrm{Nr}^{\mathrm{a}}$ & Unger data variables & $\mathrm{Nr}^{\mathrm{a}}$ \\
\hline Bank secrecy equals 1(no bank secrecy) & 134 & Bank secrecy equals 1 (no bank secrecy laws) & 103 \\
\hline Bank secrecy equals 2 & 21 & Bank secrecy equals 2 & 46 \\
\hline \multirow[t]{2}{*}{ Bank secrecy equals 3(strict bank secrecy) } & 45 & Bank secrecy equals 3 & 14 \\
\hline & & Bank secrecy equals 4 (bank secrecy laws enforced) & 36 \\
\hline Government attitude equals 1 (hostile) & 25 & Government attitude equals 1 (hostile) & 30 \\
\hline Government attitude equals 2 & 35 & Government attitude equals 2 & 70 \\
\hline Government attitude equals 2.5 & 7 & Government attitude equals 3 & 90 \\
\hline Government attitude equals 3 & 60 & Government attitude equals 4 & 4 \\
\hline Government attitude equals 4 (tolerant) & 73 & Government attitude equals 5 (tolerant) & 5 \\
\hline No swift membership & 45 & No swift membership & 12 \\
\hline Swift membership & 154 & Swift membership & 187 \\
\hline Conflict level equals 1 (peaceful country) & 118 & Conflict level equals 1 (no conflict) & 122 \\
\hline Conflict level equals 2 & 49 & Conflict level equals 2 & 29 \\
\hline Conflict level equals 3 & 21 & Conflict level equals 3 & 28 \\
\hline \multirow[t]{10}{*}{ Conflict level equals 4 (heavy conflict) } & 12 & Conflict level equals 4 & 17 \\
\hline & & Conflict level equals 5 (conflict situation) & 3 \\
\hline & & Corruption level equals 1 (low corruption) & 17 \\
\hline & & Corruption level equals 2 & 17 \\
\hline & & Corruption level equals 3 & 39 \\
\hline & & Corruption level equals 4 & 120 \\
\hline & & Corruption level equals 5 (high corruption) & 6 \\
\hline & & Member of Egmont group & 87 \\
\hline & & English is an official language & 63 \\
\hline & & Colonial relationship with US & 6 \\
\hline
\end{tabular}

${ }^{\mathrm{a}} \mathrm{Nr}$ stands for number of observations. 
Table A.3. Under- and overvaluation of US exports and imports with 25 countries (2004; billion US\$)

\begin{tabular}{|c|c|c|c|c|c|c|}
\hline & UEX & OIM & ML $^{\text {OUT }}$ & UIM & OEX & $\mathrm{ML}^{\mathrm{IN}}$ \\
\hline Column & 1 & 2 & 3 & 4 & 5 & 6 \\
\hline Australia & 0.9 & 0.9 & 1.8 & 1.2 & 1.0 & 2.2 \\
\hline Canada & 11.0 & 7.3 & 18.3 & 6.5 & 15.1 & 21.6 \\
\hline Denmark & 1.5 & 0.4 & 1.9 & 0.1 & 0.6 & 0.7 \\
\hline France & 1.3 & 1.3 & 2.6 & 2.2 & 0.9 & 3.1 \\
\hline Germany & 6.4 & 5.4 & 11.8 & 2.7 & 22.8 & 25.5 \\
\hline UK & 7.6 & 2.5 & 10.1 & 2.9 & 13.4 & 16.2 \\
\hline Italy & 1.5 & 1.5 & 3.0 & 0.8 & 8.6 & 9.4 \\
\hline Japan & 8.2 & 6.0 & 14.1 & 3.6 & 22.0 & 25.6 \\
\hline Netherlands & 2.6 & 0.5 & 3.1 & 2.4 & 3.1 & 5.5 \\
\hline Norway & 0.5 & 0.2 & 0.8 & 0.1 & 0.5 & 0.6 \\
\hline Switzerland & 2.3 & 0.7 & 3.0 & 0.4 & 4.3 & 4.7 \\
\hline Luxembourg & 0.100 & 0.009 & 0.108 & 0.020 & 0.019 & 0.039 \\
\hline Monaco & 0.000 & 0.001 & 0.001 & 0.000 & 0.009 & 0.009 \\
\hline Lichtenstein & 0.000 & 0.018 & 0.018 & 0.001 & 0.009 & 0.010 \\
\hline Barbados & 0.099 & 0.001 & 0.100 & 0.014 & 0.086 & 0.100 \\
\hline China & 6.0 & 7.8 & 13.8 & 2.6 & 17.7 & 20.3 \\
\hline Malaysia & 2.3 & 1.2 & 3.5 & 1.7 & 3.5 & 5.2 \\
\hline Philippines & 3.4 & 0.5 & 3.9 & 1.1 & 0.7 & 1.8 \\
\hline Taiwan & 3.1 & 1.7 & 4.8 & 2.4 & 4.1 & 6.4 \\
\hline Mexico & 8.8 & 4.2 & 13.0 & 5.3 & 9.4 & 14.7 \\
\hline Russia & 0.5 & 0.2 & 0.7 & 0.1 & 0.4 & 0.5 \\
\hline Senegal & 0.005 & 0.000 & 0.005 & 0.009 & 0.000 & 0.009 \\
\hline Liberia & 0.001 & 0.033 & 0.034 & 0.001 & 0.003 & 0.004 \\
\hline Botswana & 0.002 & 0.006 & 0.007 & 0.001 & 0.006 & 0.007 \\
\hline Cameroon & 0.001 & 0.024 & 0.025 & 0.005 & 0.001 & 0.007 \\
\hline Rest of world & 45.8 & 15.9 & 61.6 & 15.5 & 48.7 & 64.1 \\
\hline Total for US & 111.6 & 56.2 & 167.8 & 48.1 & 175.2 & 223.3 \\
\hline
\end{tabular}

Note: The variables are undervalued US exports (UEX), overvalued US imports $(O I M)$, their sum $\left(M L^{\text {OUT }}\right)$, overvalued US exports $(O E X)$, undervalued US imports (UIM), and their sum $\left(M L^{I N}\right)$. 
Table A.4. Under- and overvaluation of US ex- and imports as share of total US under- and overvaluation for 25 countries (2004)

\begin{tabular}{|c|c|c|c|c|c|c|c|c|}
\hline & uex & oim & $\mathrm{ml}^{\text {out }}$ & uim & oex & $\mathrm{ml}^{\text {in }}$ & ex & im \\
\hline Column & 7 & 8 & 9 & 10 & 11 & 12 & 13 & 14 \\
\hline Australia & 1.6 & 0.5 & 1.2 & 0.6 & 1.7 & 0.8 & 1.7 & 0.5 \\
\hline Canada & 9.9 & 12.9 & 10.9 & 8.6 & 13.5 & 9.7 & 23.0 & 17.4 \\
\hline Denmark & 1.3 & 0.8 & 1.1 & 0.4 & 0.2 & 0.3 & 0.3 & 0.3 \\
\hline France & 3.5 & 2.9 & 3.3 & 4.8 & 2.5 & 4.3 & 2.6 & 2.2 \\
\hline Germany & 5.7 & 9.7 & 7.1 & 13.0 & 5.6 & 11.4 & 3.8 & 5.3 \\
\hline UK & 6.8 & 4.4 & 6.0 & 7.6 & 6.0 & 7.3 & 4.4 & 3.2 \\
\hline Italy & 1.4 & 2.7 & 1.8 & 4.9 & 1.6 & 4.2 & 1.3 & 1.9 \\
\hline Japan & 7.3 & 10.6 & 8.4 & 12.6 & 7.5 & 11.5 & 6.7 & 8.8 \\
\hline Netherlands & 2.3 & 0.9 & 1.8 & 1.7 & 5.0 & 2.5 & 3.0 & 0.9 \\
\hline Norway & 0.5 & 0.4 & 0.5 & 0.3 & 0.2 & 0.3 & 0.2 & 0.4 \\
\hline Switzerland & 2.0 & 1.3 & 1.8 & 2.4 & 0.9 & 2.1 & 1.1 & 0.8 \\
\hline Luxembourg & 0.1 & 0.0 & 0.1 & 0.0 & 0.0 & 0.0 & 0.1 & 0.0 \\
\hline Monaco & 0.0 & 0.0 & 0.0 & 0.0 & 0.0 & 0.0 & 0.0 & 0.0 \\
\hline Lichtenstein & 0.0 & 0.0 & 0.0 & 0.0 & 0.0 & 0.0 & 0.0 & 0.0 \\
\hline Barbados & 0.1 & 0.0 & 0.1 & 0.0 & 0.0 & 0.0 & 0.0 & 0.0 \\
\hline China & 5.4 & 13.9 & 8.2 & 10.1 & 5.4 & 9.1 & 4.3 & 13.4 \\
\hline Malaysia & 2.1 & 2.1 & 2.1 & 2.0 & 3.5 & 2.3 & 1.3 & 1.9 \\
\hline Philippines & 3.0 & 0.9 & 2.3 & 0.4 & 2.3 & 0.8 & 0.9 & 0.6 \\
\hline Taiwan & 2.8 & 3.0 & 2.9 & 2.3 & 4.9 & 2.9 & 2.7 & 2.4 \\
\hline Mexico & 7.9 & 7.5 & 7.7 & 5.4 & 10.9 & 6.6 & 13.6 & 10.6 \\
\hline Russia & 0.4 & 0.4 & 0.4 & 0.2 & 0.3 & 0.2 & 0.4 & 0.8 \\
\hline Senegal & 0.0 & 0.0 & 0.0 & 0.0 & 0.0 & 0.0 & 0.0 & 0.0 \\
\hline Liberia & 0.0 & 0.1 & 0.0 & 0.0 & 0.0 & 0.0 & 0.0 & 0.0 \\
\hline Botswana & 0.0 & 0.0 & 0.0 & 0.0 & 0.0 & 0.0 & 0.0 & 0.0 \\
\hline Cameroon & 0.0 & 0.0 & 0.0 & 0.0 & 0.0 & 0.0 & 0.0 & 0.0 \\
\hline Rest of world & 41.0 & 28.3 & 36.7 & 27.8 & 32.2 & 28.7 & 33.0 & 31.3 \\
\hline Total & 100.0 & 100.0 & 100.0 & 100.0 & 100.0 & 100.0 & 100.0 & 100.0 \\
\hline
\end{tabular}

Note: For the variable names in Columns 7-12, see note below Table A.3. Lower cases point to shares. For the last two columns: the countries' shares in US exports (ex) and US imports (im) 
Table A.5. Ratios of US TBML outflows and licit US exports for 25 countries (2004; billion US\$)

\begin{tabular}{|c|c|c|c|c|}
\hline & uexr & oimr & uimr & oexr \\
\hline Column & 15 & 16 & 17 & 18 \\
\hline Australia & 0.93 & 0.89 & 1.17 & 0,99 \\
\hline Canada & 0.43 & 0.74 & 0.50 & 0.59 \\
\hline Denmark & 4.95 & 2.92 & 1.34 & 0.84 \\
\hline France & 1.34 & 1.34 & 2.21 & 0.95 \\
\hline Germany & 1.49 & 1.84 & 2.48 & 1.45 \\
\hline UK & 1.55 & 1.40 & 2.42 & 1.35 \\
\hline Italy & 1.05 & 1.39 & 2.58 & 1.19 \\
\hline Japan & 1.10 & 1.21 & 1.43 & 1.12 \\
\hline Netherlands & 0.77 & 1.09 & 2.04 & 1.69 \\
\hline Norway & 2.44 & 0.89 & 0.69 & 0.91 \\
\hline Switzerland & 1.80 & 1.65 & 3.09 & 0.77 \\
\hline Luxembourg & 1.03 & 0.77 & 0.53 & 0.49 \\
\hline Monaco & 0.01 & 0.63 & 3.45 & 0.02 \\
\hline Lichtenstein & 0.11 & 1.65 & 0.27 & 1.11 \\
\hline Barbados & 2.09 & 0.58 & 19.60 & 0.67 \\
\hline China & 1.27 & 1.04 & 0.76 & 1.27 \\
\hline Malaysia & 1.56 & 1.12 & 1.05 & 2.63 \\
\hline Philippines & 3.52 & 1.47 & 0.67 & 2.60 \\
\hline Taiwan & 1.04 & 1.28 & 0.98 & 1.86 \\
\hline Mexico & 0.58 & 0.70 & 0.51 & 0.81 \\
\hline Russia & 1.20 & 0.55 & 0.30 & 0.69 \\
\hline Senegal & 0.39 & 0.10 & 0.02 & 1.65 \\
\hline Liberia & 0.10 & 10.38 & 0.27 & 0.35 \\
\hline Botswana & 0.24 & 2.01 & 0.66 & 0.29 \\
\hline Cameroon & 0.05 & 2.03 & 0.04 & 0.94 \\
\hline Rest of world & 1.24 & 0.90 & 0.89 & 0.98 \\
\hline
\end{tabular}

Explanation: Canada with a 9.9 percent share of total US TBML outflow through undervalued exports and a share of 23 percent in US exports has a ratio of 0.43 . Ratios below 1 indicate relatively little TBML while ratios above 1 reflect relatively more TBML.

\section{Appendix 2: The calculations behind the Lorenz curves}

The total outflow of TBML from the US consists of the sum of undervalued US exports (denoted by $U E X)$ and overvalued US imports $(O I M)$, so $M L^{O U T}=\sum_{i}^{n}\left(U E X_{i}+O I M_{i}\right)$, where the subscript $i$ is the country index. ${ }^{20}$ This total corresponds to the upper-left hand cell in Table 2. Throughout, we use absolute values for undervaluation so that TBML is always positive. Analogously, we define overvalued US exports $(O E X)$ and undervalued US imports (UIM) and their sum total: $M L^{I N}=\sum_{i}^{n}\left(O E X_{i}+U I M_{i}\right)$, the bottom-right hand cell in Table 2. Using these variables, Table A. 3 gives an overview of these TBML values for a selection of 25 out of the 199 countries.

\footnotetext{
${ }^{20}$ Absolute amounts are expressed in capitals, percentages are in lower cases, and ratios are also in lower cases but ending with letter $r$. US export to country $i$ is denoted by $E X_{i}$ and US imports from country $i$ by $I M_{i}$. Exports can be overvalued (denoted by $\left.O E X_{i}\right)$ or undervalued $\left(U E X_{i}\right)$ and the same applies to imports $\left(O I M_{i}\right.$ and $\left.U I M_{i}\right)$, where the over- or undervaluation is measured as the difference in value evaluated against the normal price and the actual price.
} 
The share of undervalued US exports to country $i$ in the total of undervalued US exports is:

uex $_{i}=\frac{U E X_{i}}{\sum_{j=1}^{n} U E X_{j}}=\frac{U E X_{i}}{U E X_{t}}$

and likewise for the other variables (see Table A.4). So, Canada holds a share of 11.0/111.6 = 9.9 percent in undervalued US exports (Column 7), using the first and bottom rows of column 1 in table A.3. Columns 13 and 14 present the countries' shares in US exports (ex) and US imports (im). They show that Canada is the most important export and import partner of the US, followed by Mexico with respect to exports and by China with respect to imports.

For our purposes, the most interesting variables are the countries' shares of under- and overvalued US ex- and imports in the US totals relative to the countries' licit trade shares of ex- and imports in the US totals. For example, uexr $_{i}$, or the countries' shares of undervalued US exports in the US total relative to the countries' licit trade shares of exports in the US total export, is defined as:

$\operatorname{uexr}_{i}=\left(U E X_{i} / \sum_{j=1}^{n} U E X_{j}\right) /\left(E X_{i} / \sum_{j=1}^{n} E X_{j}\right)=$ uex $_{i} / \operatorname{ex}_{i}$

If a country's share of undervalued US exports would exactly be equal to its US export share, then the ratio uexr $_{i}$ is unity. If it is higher (lower) than proportional, the ratio is higher (lower) than 1 . The results of these calculations are given in Table A.5 in Appendix 1. Denmark has high ratios for undervalued exports and overvalued imports, both contributing to US TBML outflow. Barbados has a very high ratio (19.6) of undervalued imports. However, as Column 4 in Table A.3 shows, the underlying undervalued US imports from Barbados amount to only \$14 million.

\section{Appendix 3: Testing the gravity model for trade}

This appendix investigates to what extent it is possible to actually estimate a gravity model on the basis of just data flows from one country (the US in our case). Table A.6 tests whether the loglinear gravity model for trade, as formulated in Equation (1), yields results similar to the ones in the literature if we restrict our trade dataset to the same asymmetric geographical structure as our TBML dataset. 
Table A.6. A standard gravity model for US exports extended by attractiveness indicators (2004)

\begin{tabular}{lcc}
\hline & \multicolumn{2}{c}{ Basic trade model } \\
\cline { 2 - 3 } & \multicolumn{2}{c}{ standard deviation } \\
\hline GDP & $0.98^{* * *}$ & 0.21 \\
Population & -0.19 & 0.19 \\
Border dummy & $2.03^{*}$ & 1.21 \\
Common language & $0.66^{*}$ & 0.39 \\
Colonial background & $0.86^{* *}$ & 0.41 \\
Distance & $-0.92^{* * *}$ & 0.22 \\
Constant & $7.88^{* * *}$ & 3.02 \\
Nr. of observations & 199 & \\
$\mathrm{R}^{2}$, adjusted & 0.64 \\
\hline
\end{tabular}

Note: ${ }^{*}{ }^{* *}$ and ${ }^{* * *}$ indicates significance at, respectively, the $10 \%, 5 \%$ and $1 \%$ level.

The results in Table A.6 show that our results are in line with other research, such as Helpman et al. (2008).All coefficients have the expected sign and those of GDP, Colonial background and Distance are highly significant. The value on the distance coefficient is at -0.92 fully in line with the commonly found estimate of around -0.9. This indicates that the standard gravity model applies satisfactorily to the restricted, asymmetric dataset. This result leads us to conclude that despite the fact that we use data on flows from the US only, coefficients on the most important variables of the gravity model, GDP and distance, are in line with other studies. 